\title{
Construct validity, dimensionality and factorial invariance of the Rosenberg Self-Esteem Scale: a bifactor modelling approach among children of prisoners
}

\author{
Kathryn Sharratt ${ }^{E, F}$, Daniel Boduszek ${ }^{C, D, E}$, Adele fones ${ }^{A, B, E}$, Bernard Gallagher ${ }^{E}$ \\ University of Huddersfield, Huddersfield, UK
}

\section{BACKGROUND}

The Rosenberg Self-Esteem Scale (RSES) has traditionally been conceptualised as a unidimensional measure of self-esteem, but empirical evidence is equivocal, with some studies supporting a one-factor solution and others favouring multidimensional models.

PARTICIPANTS AND PROCEDURE

The aim of this study was to examine the factor structure, factorial invariance and composite reliability of the RSES within a European sample of children affected by parental imprisonment $(N=724)$. The study specified and tested six alternative factor models using conventional confirmatory factor analytic (CFA) techniques and a confirmatory bifactor modelling approach.

\section{RESULTS}

The RSES was most effectively represented by a bifactor model including a general self-esteem factor comprising all ten scale items and separate method effects for the positively and negatively phrased items. This model was found to be factorially invariant among boys and girls. Composite reliability indicated good internal consistency for the general self-esteem dimension but slightly less so for the positive and negative method effects.

\section{CONCLUSIONS}

It follows that the calculation of a total RSES score is appropriate for children of prisoners, providing that the presence of method effects is taken into consideration to avoid giving rise to false interpretations. This study demonstrated the application of a bifactorial modeling approach as a potential solution.

\section{KEY WORDS}

Rosenberg Self-Esteem Scale (RSES); bifactor modelling; confirmatory factor analysis; factorial invariance; children of prisoners

CORRESPONDING AUthor - Daniel Boduszek, Ph.D., University of Huddersfield, Queensgate, Huddersfield,

West Yorkshire HD1 3DH, UK, e-mail: d.boduszek@hud.ac.uk

AUthors' CONTRIBUtion - A: Study design - B: Data collection - C: Statistical analysis - D: Data interpretation .

E: Manuscript preparation · F: Literature search $\cdot$ G: Funds collection

TO CITE THIS ARTICLE - Sharratt, K., Boduszek, D., Jones, A., \& Gallagher, B. (2014). Construct validity, dimensionality

and factorial invariance of the Rosenberg Self-Esteem Scale: a bifactor modelling approach among children

of prisoners. Current Issues in Personality Psychology, 2(4), 228-236.

RECEIVED 21.10.2014 · REVIEWED 25.10.2014 · ACCEPTED 06.11.2014 · PUBLISHED 08.12.2014 


\section{BACKGROUND}

Qualitative studies have variously demonstrated that children affected by parental imprisonment suffer feelings of sadness, despair, loss, rejection, confusion and anxiety (e.g. Bocknek, Sanderson, \& Britner, 2009; Jones et al., 2013). Combined with exposure to secondary stigma, social isolation, bullying and victimization (e.g. Cunningham, 2001; Murray, 2007), it would not be surprising if parental imprisonment was found to have deleterious consequences to self-esteem. Indeed, during the course of interviews, children of prisoners have been reported to express feelings such as shame, guilt and embarrassment that could be considered synonymous with low self-esteem (Brown, Dibb, Shenton, \& Elson, 2000; Hissel, Bijleveld, \& Kruttschnitt, 2011). This is cause for concern given that empirical evidence suggests lower levels of self-esteem play an important role in the development of clinical depression, whereas higher levels of self-esteem can promote resilience in response to adverse life events (see Pyszczynski, Greenberg, Solomon, Arndt, \& Schimel, 2004 for a review). Taking into consideration research that has demonstrated that boys and girls react differently to parental imprisonment, with boys displaying more externalising problems and girls more internalising problems (Murray, Farrington, Sekol, \& Olsen, 2009; Murray \& Farrington, 2008), gender differences in self-esteem might also be anticipated in response to parental imprisonment.

Despite the findings that have emerged from qualitative research, very few studies have adopted a robust quantitative approach to measuring the self-esteem of children of prisoners, i.e. through the application of standardised instruments. Although research in this area is limited, it does suggest that there might be some utility in examining the contribution of caregiving arrangements and interventions in supporting positive self-esteem outcomes for children of prisoners. Hanlon et al. (2005), for example, administered the Piers-Harris Children's Self-Concept Scale (Piers, 1984) to children with incarcerated mothers and revealed levels of self-esteem comparable to the general population. It was suggested that the children's positive adjustment was a consequence of the consistent and nurturing environment provided by their caregiver (mostly grandmothers). Conversely, Springer, Lynch and Rubin (2000) administered the Hare Self-Esteem Scale (Hare, 1980) to children of prisoners who had participated in a group-based intervention and revealed no significant improvement in self-esteem. Utilising the Self-Perception Profile for Children and for Adolescents (Harter, 1985, 1988), Harrison (1997) demonstrated that a parenting programme for prisoners had no significant impact on the self-esteem of the participants' children.
As illustrated above, various instruments have been designed to measure self-esteem amongst children and young people, but the Rosenberg Self-Esteem Scale (RSES; Rosenberg, 1989) remains one of the most commonly used. Rosenberg (1965) initially described self-esteem as a component of the self-concept in which individuals hold favourable or unfavourable perceptions about themselves in terms of their worth and importance. The RSES was originally designed to measure self-esteem as a single construct, but despite its widespread use, there remains uncertainty with regards to the number of latent variables that effectively explain the underlying structure of the instrument.

Through the application of confirmatory factor analysis (CFA), a number of researchers have found support for a one-factor solution (e.g. Dunbar, Ford, Hunt, \& Der, 2000; Gana, Alaphilippe, \& Bailly, 2005; Shevlin, Bunting, \& Lewis, 1995). Other studies, however, have suggested that multi-factorial solutions might be more appropriate (see Huang \& Dong, 2012 for a review). This includes a large body of literature indicating that items load onto two distinct factors, one representing positive evaluations of the self and one representing negative evaluations of the self (e.g. Carmines \& Zeller, 1979; Kaufman, Rasinski, Lee, \& West, 1991). A crucial concern is whether these latter findings reflect two substantially different latent factors or are a consequence of an unwanted method effect arising from the positive and negative phrasing of items (Bagozzi, 1993).

In an attempt to provide clarification, Marsh (1996) tested six possible model solutions and found support for a single common factor and a method factor primarily consisting of the negatively worded items. Marsh (1996) suggested that the younger, less verbally able students in the sample might have experienced more difficulties responding to the negatively phrased items. However, this study utilised a 7-item version of the scale, limiting the number of items per factor and the comparability of the instrument to the full 10-item version. In an extension to the previous study, Corwyn (2000), Tomás and Oliver (1999) and Quilty, Oakman and Risko (2006) administered the full ten-item version of the scale to high school students and young people, and confirmed the presence of a single latent variable with negative item method effects.

More recently, investigators have administered the RSES to representative samples of adolescents (Marsh, Scalas, \& Nagengast, 2010) and adults (Hyland, Boduszek, Dhingra, Shevlin, \& Egan, 2014) and have comprehensively tested a series of traditional CFA models in addition to a variety of bifactor model conceptualisations. Bifactor modelling techniques were developed for use in situations where both single and multidimensional latent structures seem to provide an adequate representation of the 
scale (Reise, Moore, \& Haviland, 2010; Reise, Morizot, $\&$ Hays, 2007), as with the RSES. In conventional CFA models, covariation between scale items is assumed to be explained in terms of one or more latent constructs, whereas in bifactor modelling, covariation amongst scale items is assumed to be explained by both "general factors" and "grouping factors" which exist at the same conceptual level. This enables the researcher to model a single self-esteem factor proposed to account for most of the item covariation in addition to two separate grouping factors to account for the positive and negative method factors emerging as a result of item wording. The bifactor modelling approach, therefore, has the added benefit of being able to distinguish between error variance and method variance and genuine latent constructs. Marsh et al. (2010) and Hyland et al. (2014) found no support for the one-factor model, and similarly, very little support for the two-factor model. There was, however, strong support for a bifactor solution comprising a single general self-esteem factor and two method/grouping factors reflecting positive and negative method effects.

Boduszek and colleagues have also tested a series of conventional CFA models and bifactor models of the RSES amongst samples of prisoners, and found that superior fit was achieved with a two-factor model comprising separate positive and negative latent variables (Boduszek, Hyland, Dhingra, \& Mallet, 2013; Boduszek, Shevlin, Mallet, Hyland, \& O'Kane, 2012). Carmines and Zeller (1979) argue that if the positive and negative dimensions are indeed measuring substantially different aspects of self-esteem, then they should differentially relate to external variables. In further support of the two-factor model, positive (but not negative) self-esteem was found to be a significant predictor of recidivism (Boduszek et al., 2013), and negative (but not positive) self-esteem was found to be a significant predictor of criminal cognitions (Boduszek et al., 2012).

In summary, empirical evidence suggests that the RSES measures a single general self-esteem factor amongst children and young people (with the addition of positive and negative method effects), but amongst prisoners it is more effectively represented by two distinct positive and negative self-esteem factors. This raises an important question with regards to children affected by parental imprisonment: does the underlying factor structure of the RSES amongst this group of children resemble that of their peers or that of their imprisoned parents? Therefore, the first aim of this study was to advance knowledge with regards to the application of standardised self-esteem measures to children of prisoners, namely the RSES, by investigating the underlying factor structure amongst a large European sample. In order to achieve this, a series of six competing models of the RSES were specified and tested using a combination of conventional CFA techniques and a confirmatory bifactor modelling approach. It was also apparent from the literature review that there are a growing number of studies concerned with identifying differential reactions to parental imprisonment among boys and girls. This underscores the importance of identifying instruments that can provide a reliable indication of differences in the psychological adjustment of boys and girls. Therefore, the second aim of the paper was to examine the factorial invariance of the RSES among boys and girls. The third aim of the paper was to examine the composite reliability of the RSES among children of prisoners, thereby providing a more robust indication of internal reliability than the more frequently used Cronbach's $\alpha$ scores.

\section{PARTICIPANTS AND PROCEDURE}

\section{PARTICIPANTS}

The sample consisted of 724 children from the UK, Germany, Romania and Sweden who were affected by the imprisonment of a parent or carer. Participants were mainly recruited by non-governmental organisations as part of their normal work at prison visitor centres and counselling centres. Participants were 393 boys and 331 girls aged from 7 to 17 years $(M=11.27, S D=3.12)$. Data on ethnicity were only available for the UK and Romania, where the majority of children were White (86.80\%). Most children in the sample had a biological father in prison $(73.00 \%)$ and were currently living with their biological mother $(73.30 \%)$. Imprisoned parents had committed a variety of offences, and had served between one month and 15 years in prison $(M=2.50, S D=2.70)$. The majority of children had maintained at least some contact with their imprisoned parent (via prison visits, telephone calls or letter writing; $91.20 \%$ ).

\section{MEASURE}

The RSES consists of 10 Likert-type scale items designed to assess positive and negative evaluations of self. Respondents indicate their level of agreement ranging from 1 (strongly disagree) to 4 (strongly agree). Thus, the possible total score can range from a minimum of 10 to a maximum of 40 , with higher scores reflecting more positive evaluations of self. This study utilised the English, German, Swedish and Romanian translation of the scale as appropriate.

\section{ANALYSIS}

The dimensionality of the RSES was investigated through the use of conventional confirmatory factor 
analytic (CFA) techniques, along with the utilization of a confirmatory bifactor modelling approach (see Reise et al., 2010; Reise et al., 2007). Six alternative models of the latent factor structure of the RSES were specified and estimated using Mplus version 6.0 (Muthen \& Muthen, 1998-2010) with maximum likelihood (ML) estimation. Three of these models were traditional CFA conceptualizations with items restricted to load only onto a single factor. In the bifactor models, each item was allowed to load onto a general factor (self-esteem) and one grouping factor (positive self-esteem or negative self-esteem). Within a bifactor model, the grouping factors are restricted to be uncorrelated with each other and uncorrelated with the general self-esteem factor. For the purposes of model identification, the variance of each factor is set to 1.0 .

The following six models were specified and estimated as follows: (a) Model 1, a 10-item unidimensional model; (b) Model 2, 10 items and two correlated factors (positively and negatively orientated items); (c) Model 3, 10 items and two independent factors (positively and negatively orientated items); (d) Model 4, one global self-esteem factor and two correlated method factors that include the positive items on the one hand and the negative items on the other; (e) Model 5, one global self-esteem factor and one method factor that includes the positive items; (f) Model 6, one global self-esteem factor and one method factor that includes the negative items (see Fig. 1). In all cases measurement error terms remained uncorrelated as per recommendations (Brown, 2006).

The overall fit of each model and the relative fit between models were assessed using a range of goodness-of-fit statistics and assessment of the appropriateness of the model parameters. The $\chi^{2}$ statistic assessed the sample and implied covariance matrix, and a good fit of the model is indicated by a non-significant result. However, the $\chi^{2}$ statistic is strongly associated with sample size, and as such good models tend to be over-rejected. Therefore Tanaka (1987) suggested that a model should not be rejected simply on the basis of a significant $\chi^{2}$ result. Accordingly, it is recommended that researchers examine the ratio of the $\chi^{2}$ value to the degrees of freedom (df), and according to Kline (1994), any model with a $\chi^{2}$-to-df ratio of less than $3: 1$ represents a well fitting model. The Comparative Fit Index (CFI; Bentler, 1990) and the Tucker-Lewis index (TLI; Tucker \& Lewis, 1973) are measures of how much better the model fits the data compared to a baseline model where all variables are uncorrelated. For these indices values above 95 indicated good model fit (Bentler, 1990; Hu $\&$ Bentler, 1999). In addition, two more absolute indices are presented: the standardized root mean-square residual (SRMR; Joreskog \& Sorborn, 1981) and the root mean-square error of approximation (RMSEA; Steiger, 1990). Ideally these indices should be less than .05 (Bentler, 1990; Hu \& Bentler, 1999; Joreskog
\& Sorbom, 1993). Furthermore, the Akaike Information Criterion (AIC; Akaike, 1974) was used to evaluate the alternative models, with the smaller value indicating the best fitting model.

\section{RESULTS}

The mean RSES score for the entire sample was 30.58 $(S D=4.88)$. The mean scores for boys $(M=30.82$, $S D=4.75)$ and girls $(M=30.31, S D=5.02)$ were similar and not significantly different; $t(657)=1.33, p=.180$.

\section{MODEL RESULTS AND TEST OF FACTORIAL INVARIANCE}

Table 1 reports the fit indices and comparative fit indices of the six alternative models of the RSES. Based on these results, Models 1 and 3 were rejected as poor approximations of the data. Models 2, 4, 5, and 6 were found to be good representations of the data; however, substantial improvements were observed across all fit indices for Model 4. This model, which includes a single SE factor and two grouping factors (P and N), was determined to be the best approximation of the covariation matrix in the obtained data based on all fit indices. This model also displayed a considerably lower AIC value than the alternative models, further indicating its statistical superiority.

The adequacy of this model can also be determined in relation to its parameter estimates. As can be seen in Table 2, all items displayed statistically significant $(p<.001)$ factor loadings on the general SE factor. Further inspection of the factor loadings for the two grouping factors (P and $\mathrm{N}$ ) provides critical information regarding the appropriateness of including these factors in the scoring of the RSES. Reise et al. (2010) advise that when items load strongly onto a general factor, and weaker on each of the grouping factors, this provides support for consideration of a unidimensional scoring scheme. Alternatively, when items load as strongly, or more strongly, onto each of the respective grouping factors than they do onto the general factor, creation of subscales is appropriate.

As outlined in Table 2, factor loadings on the general SE factor were in the expected direction and were stronger than those on the grouping factors. Most of the negatively worded items ( $\mathrm{N}$ factor) have statistically non-significant factor loadings $(p>.050)$; however, the $\mathrm{P}$ factor in particular displayed robust factor loadings. These parameter estimate results provide strong support for the supremacy of a single SE latent factor and the presence of two meaningful method effect factors.

Subsequently, tests of factorial invariance were conducted between boys $(n=393)$ and girls $(n=331)$ using the bifactor solution as the baseline model. 

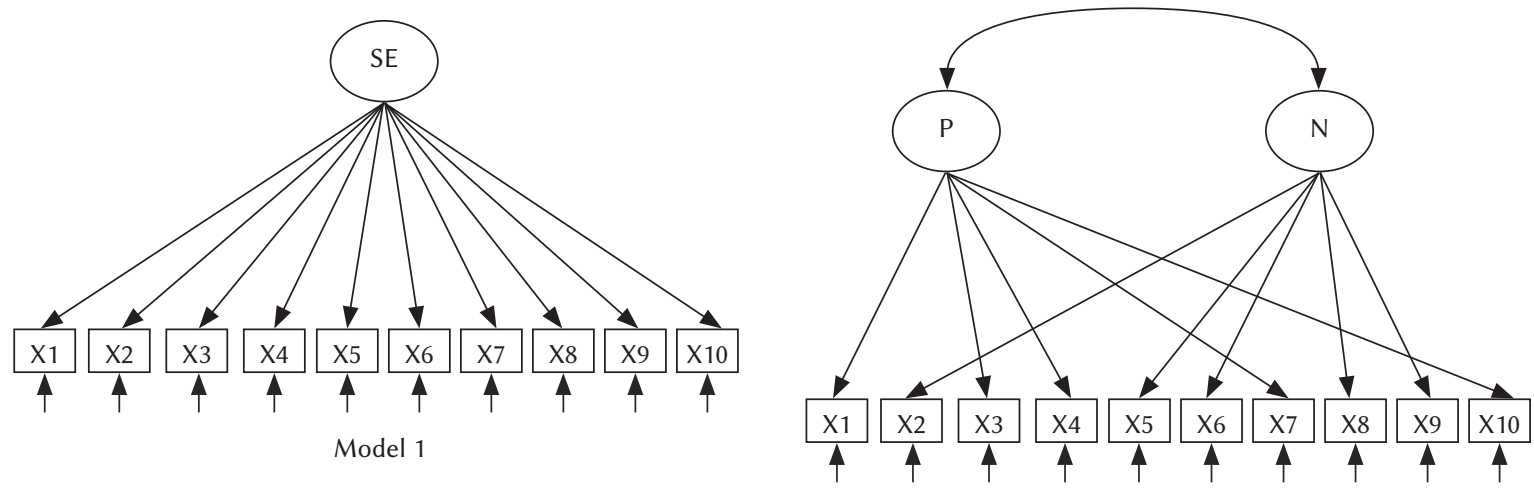

Model 2
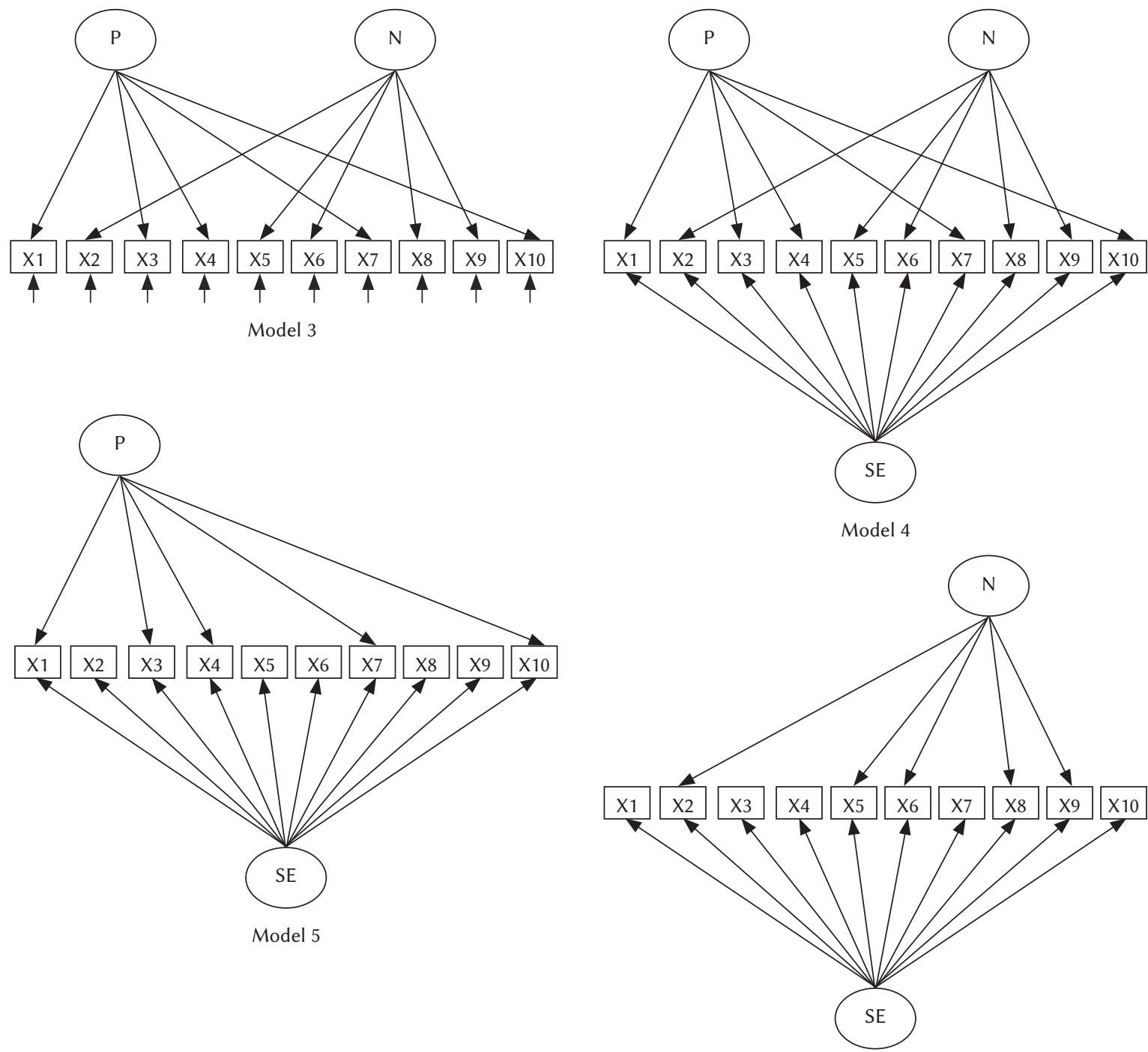

Figure 1. Alternative Factor Models of Rosenberg Self-Esteem Scale.

Model 6

Following the procedure of Bollen (1989), a hierarchy of increasingly restrictive models was specified and tested. The test of invariance of form, or that the bifactor model held in both samples, was supported, $\chi^{2}=80.91, d f=50, p=.004($ RMSEA $=.04[90 \%$ $\mathrm{CI}=.02 / .06]$, CFI $=.99$, TLI $=.97$, SRMR $=.03$ ), as was the test of equal factor loadings, $\chi^{2}=94.85, d f=70$,
$p=.030(\mathrm{RMSEA}=.03[90 \% \mathrm{CI}=.01 / .05], \mathrm{CFI}=.98$, $\mathrm{TLI}=.98, \mathrm{SRMR}=.05)$. Assessment of invariance in factor variances could not be conducted due to the necessity to constrain factor variances to 1 in order that a bifactor solution could be identified. These results indicate that the RSES is factorially invariant between boys and girls. 
Table 1

Fit Indices for Six Alternative Models of the Rosenberg Self-Esteem Scale

\begin{tabular}{cccccccc}
\hline & $\chi^{2}$ & $d f$ & CFI & TLI & RMSEA & SRMR & AIC \\
\hline Models & & & & & & & \\
Model 1 & $474.50^{*}$ & 35 & .78 & .72 & .14 & .09 & 14548.74 \\
Model 2 & $99.94^{*}$ & 34 & .97 & .96 & .05 & .04 & 14176.18 \\
Model 3 & $248.36^{*}$ & 35 & .89 & .86 & .09 & .16 & 14322.60 \\
Model 4 & $48.30^{*}$ & 25 & .99 & .98 & .04 & .02 & 14142.54 \\
Model 5 & $84.62^{*}$ & 30 & .97 & .96 & .05 & .03 & 14168.86 \\
Model 6 & $79.90^{*}$ & 30 & .98 & .96 & .05 & .03 & 14164.14 \\
\hline
\end{tabular}

Note. $N=724 ; \chi^{2}$ - chi-square goodness of fit statistic; $d f$ - degrees of freedom; RMSEA - root-mean-square error of approximation; CI - confidence interval; AIC - Akaike Information Criterion; CFI - comparative fit index; TLI - Tucker-Lewis index; SRMR - standardized square root mean residual. ${ }^{*}$ Indicates $\chi^{2}$ is statistically significant $(p<.050)$.

Table 2

Standardized Factor Loadings for the General Factor and Two-Method Factors of the Rosenberg Self-Esteem Scale

\begin{tabular}{|c|c|c|c|}
\hline Items & $\begin{array}{l}\beta \text { (general } \\
\text { factor) }\end{array}$ & $\begin{array}{c}\beta \text { (positive } \\
\text { method } \\
\text { factor) }\end{array}$ & $\begin{array}{c}\beta \text { (negative } \\
\text { method } \\
\text { factor) }\end{array}$ \\
\hline 1. On the whole, I am satisfied with myself & $0.42^{* * *}$ & $0.41^{* * *}$ & \\
\hline 2. At times, I think I am no good at all & $0.63^{* * *}$ & & $0.62^{* * *}$ \\
\hline 3. I feel that I have a number of good qualities & $0.37^{* * *}$ & $0.55^{* * *}$ & \\
\hline 4. I am able to do things as well as most other people & $0.37^{* * *}$ & $0.62^{* * *}$ & \\
\hline 5. I feel I do not have much to be proud of & $0.60^{* * *}$ & & 0.13 \\
\hline 6. I certainly feel useless at times & $0.68^{* * *}$ & & $0.31^{* *}$ \\
\hline $\begin{array}{l}\text { 7. I feel that I'm a person of worth, at least on an equal } \\
\text { plane with others }\end{array}$ & $0.30 * * *$ & $0.52^{* * *}$ & \\
\hline 8. I wish I could have more respect for myself & $0.61^{* * *}$ & & 0.10 \\
\hline 9. All in all I am inclined to feel that I am a failure & $0.76^{* * *}$ & & 0.04 \\
\hline 10. I take a positive attitude towards myself & $0.44^{* * *}$ & $0.46^{* * *}$ & \\
\hline
\end{tabular}

Note. Factor loadings statistically significant at ${ }^{* *} p<.001,{ }^{* *} p<.010,{ }^{*} p<.050$.

\section{RELIABILITY ANALYSIS}

The use of traditional measures of internal reliability such as Cronbach's $\alpha$ has been criticised within a latent variable modelling context given the propensity to over - or under-estimate scale reliability (see Raykov, 1998). In order to provide a more rigorous assessment of the internal reliability of the RSES, the current study investigated the composite reliability of the measurement properties of the scale. Composite reliability was calculated using the formula:

$$
\rho_{c}=\frac{\left(\sum_{i=1}^{m} \lambda_{i}\right)^{2}}{\left(\sum_{i=1}^{m} \lambda i\right)^{2}+\left(\sum_{i=1}^{m}\left(0_{i}\right)\right)}
$$

Where $\rho_{c}=$ reliability of the factor score, $\lambda_{\mathrm{i}}=$ standardized factor loading, and $\theta_{\mathrm{i}}=$ standardised error variance. Values greater than .60 are generally considered acceptable (Bagozzi \& Yi, 1988; Diamantopoulos \& Siguaw, 2000). Current results indicate that the general SE factor of the RSES possesses good internal consistency $\left(\rho_{c}=.84\right)$. In contrast, the internal reliability for the two grouping factors was lower $\left(\mathrm{P}, \rho_{c}=.68\right.$, $\left.\mathrm{N}, \rho_{c}=.38\right)$.

\section{DISCUSSION}

Previous literature suggests that there is utility in studying the impact of parental imprisonment on children's self-esteem, especially to identify factors that might mediate the potential for adverse outcomes (Hanlon et al., 2005; Springer, Lynch, \& Ru- 
bin, 2000). Despite this, relatively few studies have administered standardised measures of self-esteem to this group of children. Therefore, the aim of the present study was to advance knowledge with regards to the application of standardised self-esteem measures to children of prisoners, namely the Rosenberg Self-Esteem Scale (RSES; Rosenberg, 1989). Six alternative models of the RSES were specified and tested using conventional CFA techniques and a confirmatory bifactor modelling approach. Based on several fit indices, a bifactor model comprising a single common self-esteem factor and positive and negative grouping factors was considered to provide an adequate fit, and was superior to alternative solutions. Item loadings and composite reliability scores were better for the single factor than the grouping factors, further reinforcing the supremacy of a general self-esteem factor.

These findings are consistent with Rosenberg's (1965) initial unidimensional conceptualisation of self-esteem, and also previous research conducted within general population samples of children and young people that has revealed superior fit for solutions incorporating a unidimensional self-esteem factor with the addition of positive and/or negative method effects (e.g. Corwyn, 2000; Marsh et al., 2010; Tomás \& Oliver, 1999). In contrast, little support was found for the existence of two distinct positive and negative self-esteem factors as evidenced among samples of prisoners (Boduszek et al., 2013; Boduszek et al., 2012). Therefore, the underlying latent variable structure of the RSES in the present sample of children of prisoners was found to be more similar to that of their peers than that of their imprisoned parents.

It follows that the calculation of total RSES scores is appropriate for children of prisoners (and children more generally), but researchers should be aware that the results might be contaminated by the presence of method effects. Simply calculating a unidimensional score with no consideration of method effects might give rise to false interpretations, for example, in relation to the effectiveness of interventions in mediating the impact of parental imprisonment on children's self-esteem. This study has highlighted the importance of allowing for methods effects by appropriately including them in latent variable models, and has demonstrated the application of a bifactorial modelling approach as a potential solution.

It should be noted that in order to meaningfully test for gender differences, any standardised instrument should produce the same or "invariant" factor structures for males and females (Rock, Werts, \& Flaugher, 1978). Indeed, the present study revealed that the bifactor model with a general self-esteem factor and positive and negative grouping factors provided an adequate fit for both boys and girls, therefore permitting the comparison of RSES scores between girls and boys affected by parental imprisonment.
This study has provided further clarification of the factor structure of the RSES and offers important directions for furthering research with children of prisoners; however, it is not without limitations. The present study was unable to confirm the applicability of the measure to other sub-samples of children of prisoners. In particular, due to the lower rates of imprisonment of women in the four countries (approximately 5\%; Aebi \& Delgrande, 2013) it was comparatively difficult to recruit children with a mother in prison. Also, since most children were recruited by NGOs designed to facilitate contact between children and their imprisoned parent, most children in the sample had contact on a regular basis.

In summary, the RSES was most effectively represented by a single common self-esteem factor and positive and negative grouping factors. This solution was found to be factorially invariant among boys and girls, facilitating the comparison of gender differences in responses to parental imprisonment. However, neglecting to take into consideration the potential for method effects by allowing for the method variance to be removed from the model might result in inaccurate conclusions.

This article is based on data collected during the COPING Project (Children of Prisoners, Interventions and Mitigations to Strengthen Mental Health), funded by the European Union Seventh Framework Programme (grant agreement number 241988) and conducted in Germany, Romania, Sweden and the UK. The consortium comprised the University of Huddersfield, Partners of Prisoners and Families Support Group, Eurochips, Technische Universitaet Dresden, Treffpunkt e.V., Universitatea Alexandru Ioan Cuza, Asociatia Alternative Sociale, the Karolinska Institutet, Riksbryggan and the Quaker United Nations Office. Lead Investigators were: Adele fones (Principal Investigator), Liz Ayres, Anne E. Berman, Bernard Gallagher, Cristina Gavriluta, Alex Hirschfield, Martin Manby, Oliver Robertson and Matthias Schuetzwohl.

\section{REFERENCES}

Aebi, M. F., \& Delgrande, N. (2013). Council of Europe Annual Penal Statistics SPACE 1, 2011 Survey on Prison Populations. Strasbourg: Council of Europe. Akaike, H. (1974). A new look at the statistical model identification. IEEE Transactions on Automatic Control, 19, 716-723.

Bagozzi, R. P. (1993). Assessing construct validity in personality research: Applications to measures of self-esteem. Journal of Research in Personality, 27, 49-87.

Bagozzi, R. P., \& Yi, Y. (1988). On the evaluation of structural equation models. Journal of the Academy of Marketing Science, 16, 74-94. 
Bentler, P. M. (1990). Comparative fit indices in structural models. Psychological Bulletin, 107, 238-246.

Bocknek, E. L., Sanderson, J., \& Britner, P. A. (2009). Ambiguous loss and posttraumatic stress in school-age children of prisoners. Journal of Child and Family Studies, 18, 323-333.

Boduszek, D., Hyland, P., Dinghra, K., \& Mallet, J. (2013). The factor structure and composite reliability of the Rosenberg Self-Esteem Scale among ex-prisoners. Personality and Individual Differences, 55, 877-887.

Boduszek, D., Shevlin, M., Mallett, J., Hyland, P., \& O'Kane, D. (2012). Dimensionality and construct validity of the Rosenberg Self-Esteem Scale within a sample of recidivistic prisoners. Journal of Criminal Psychology, 2, 19-25.

Bollen, K. A. (1989). Structural equations with latent variables. New York: John Wiley \& Sons, Inc.

Brown, T. A. (2006). Confirmatory factor analysis for applied research. New York: The Guilford Press.

Brown, K., Dibb, L., Shenton, F., \& Elson, N. (2000). No-One's Ever Asked Me: Young People with a Prisoner in the Family. London: Action for Prisoners Families.

Carmines, E. G., \& Zeller, R. A. (1979). Reliability and validity assessment. Beverly Hills, CA: Sage.

Corwyn, R. F. (2000). The factor structure of global self-esteem among adolescents and adults. Journal of Research in Personality, 34, 357-379.

Cunningham, A. (2001). Forgotten Families - the impacts of imprisonment. Family Matters, 59, 36-37.

Diamantopoulos, A., \& Siguaw, J. A. (2000). Introducing LISREL. London: Sage Publications.

Dunbar, M., Ford, G., Hunt, K., \& Der, G. (2000). Question wording effects in the assessment of global self-esteem. European Journal of Psychological Assessment, 16, 13-19.

Gana, K., Alaphilippe, D., \& Bailly, N. (2005). Factorial Structure of the French Version of the Rosenberg Self-Esteem Scale Among the Elderly. International Journal of Testing, 5, 169-176.

Hanlon, T. E., Blatchley, R. J., Bennett-Sears, T., O'Grady, K. E., Rose, M., \& Callaman, J. M. (2005). Vulnerability of children of incarcerated addict mothers: Implications for preventive intervention. Children and Youth Services Review, 27, 67-84.

Hare, G. R. (1980). Self-perception and academic achievement: Variations in a desegregated setting. American Journal of Psychiatry, 137, 683-689.

Harrison, K. (1997). Parental training for incarcerated fathers: effects on attitudes, self-esteem, and children's self-perceptions. The Journal of Social Psychology, 137, 588-593.

Harter, S. (1988). Manual for the Self-Perception Profile for Adolescents. Denver: University of Denver.

Harter, S. (1985). Manual for the Self-Perception Profile for Children. Denver: University of Denver.
Hissel, S., Bijleveld, C., \& Kruttschnitt, C. (2011). The well-being of children of incarcerated mothers: An exploratory study for the Netherlands. European Journal of Criminology, 8, 346-360.

Hu, L., \& Bentler, P. M. (1999). Cutoff criteria for fit indexes in covariance structure analysis: Conventional criteria versus new alternatives. Structural Equation Modelling, 6, 1-55.

Huang, C., \& Dong, N. (2012). Factor structures of the Rosenberg Self-Esteem Scale: A meta-analysis of pattern matrices. European Journal of Psychological Assessment, 28, 132-138.

Hyland, P., Boduszek, D., Dhingra, K., Shevlin, M., \& Egan, A. (2014). A bifactor approach to modelling the Rosenberg Self-Esteem Scale. Personality and Individual Differences, 66, 188-192.

Jones, A., Gallagher, B., Manby, M., Robertson, O., Schützwohl, M., Berman, A., Hirschfield, A., Ayre, L., Urban, M., Sharratt, K., \& Christmann, K. (2013). Children of Prisoners: Interventions and mitigations to strengthen mental health. Huddersfield: University of Huddersfield.

Joreskog, K., \& Sorbom, D. (1981). LISREL V: Analysis of linear structural relationships by the method of maximum likelihood. Chicago: National Educational Resources.

Kaufman, P., Rasinski, K. A., Lee, R., \& West, J. (1991). National Education Longitudinal Study of 1988. Quality of the responses of eighth-grade students in NELS88. Washington, DC: US Department of Education.

Kline, P. (1994). An easy guide to factor analysis. New York: Routledge.

Marsh, H. M. (1996). Positive and negative global self-esteem: A substantial meaningful distinction or artifactors? Journal of Personality and Social Psychology, 70, 810-819.

Marsh, H. W., Scalas, L. F., \& Nagengast, B. (2010). Longitudinal tests of competing factor structures for the Rosenberg Self-Esteem Scale: Traits, ephemeral artifacts, and stable response styles. Psychological Assessment, 22, 366-381.

Murray, J. (2007). The cycle of punishment: Social Exclusion of Prisoners and their children. Criminology and Criminal Justice, 7, 55-81.

Murray, J., \& Farrington, D. P. (2008). Parental imprisonment: Long-lasting effects on boys' internalizing problems through the life course. Development and Psychopathology, 20, 273-290.

Murray, J., Farrington, D. P., Sekol, I., \& Olsen, R. F. (2009). Effects of parental imprisonment on child antisocial behaviour and mental health: a systemat ic review. Campbell Systematic Reviews.

Muthen, L. K., \& Muthen, B. O. (1998). Mplus - Statistical analysis with latent variables. User's guide $\left(6^{\text {th }}\right.$ ed.). Los Angeles: Muthen and Muthen. 
Piers, E. V. (1984). Piers-Harris children's self-concept scale revised manual. Los Angeles, CA7 Western Psychological Services.

Pyszczynski, T., Greenberg, J., Solomon, S., Arndt, J., \& Schimel, J. (2004). Why do people need self-esteem? A theoretical and empirical review. Psychological Bulletin, 130, 435.

Quilty, L. C., Oakman, J. M., \& Risko, E. (2006). Correlates of the Rosenberg Self-Esteem Scale Method Effects, Structural Equation Modeling. A Multidisciplinary Journal, 13, 99-117.

Raykov, T. (1998). Coefficient alpha and composite reliability with interrelated nonhomogeneous items. Applied Psychological Measurement, 22, 375-385.

Reise, S. P., Morizot, J., \& Hays, R. D. (2007). The role of the bifactor model in resolving dimensionality issues in health outcomes measures. Quality of Life Research, 16, 19-31.

Reise, S. P., Moore, T. M., \& Haviland, M. G. (2010). Bifactor models and rotations: Exploring the extent to which multidimensional data yield univocal scale scores. Journal of Personality Assessment, 92, 544-559.

Rock, D. A., Werts, C. E., \& Flaugher, R. L. (1978). The use of analysis of covariance structures for comparing the psychometric properties of multiple variables across populations. Multivariate Behavioural Research, 13, 403-418.

Rosenberg, M. (1965). Society and the adolescent self-image. Princeton, NJ: Princeton University Press.

Rosenberg, M. (1989). Society and the adolescent self-image (rev. ed.). Middeltown, CT: Wesleyan University Press.

Shevlin, M., Bunting, B. P., \& Lewis, C. A. (1995). Confirmatory factor analysis of the Rosenberg Self-Esteem Scale. Psychological Reports, 76, 707710.

Springer, D. W., Lynch, C., \& Rubin, A. (2000). Effects of a solution-focused mutual aid group for Hispanic children of incarcerated parents. Child and Adolescent Social Work Journal, 17, 431-442.

Steiger, J. H. (1990). Structural model evaluation and modification: An interval estimation approach. Multivariate Behavioural Research, 25, 173-180.

Tanaka, J. S. (1987). How big is big enough? Sample size and goodness of fit in structural equation models with latent variables. Child Development, 58, 134-146.

Tomás, J. M., \& Oliver, A. (1999). Rosenberg's Self-Esteem Scale: Two factors or method effects. Structural Equation Modeling, 6, 84-98.

Tucker, L. R., \& Lewis, C. (1973). The reliability coefficient for maximum likelihood factor analysis. Psychometrika, 38, 1-10. 